\title{
EDUCAÇÃO BÁSICA NO ESTADO DE MATO GROSSO, BRASIL: A CONSTRUÇÃO E DIVULGAÇÃO DAS ORIENTAÇÕES CURRICULARES DA ÁREA DE LINGUAGENS*
}

\author{
EDUCACION BÁSICA EN EL ESTADO DE MATO GROSSO, BRASIL: LA ELABORACIÓN Y DIVULGACIÓN \\ DE LAS DIRECTRICES CURRICULARES PARA LA ÁREA DE LINGUAGENS
}
BASIC EDUCATION IN THE STATE OF MATO GROSSO, BRAZIL: BUILDING AND DISSEMINATING CURRICULUM GUIDELINES FOR THE LANGUAGE AREA

\author{
Leandra Ines Seganfredo Santos** \\ Universidade do Estado de Mato Grosso - UNEMAT, Sinop, BR \\ Rosinda de Castro Guerra Ramos ${ }^{* * *}$ \\ Pontifícia Universidade Católica de São Paulo - PUC, São Paulo, BR \\ Sara Cristina Gomes Pereira ${ }^{1}$ \\ Centro de Formação e Atualização dos Profissionais da Educação Básica \\ do Estado de Mato Grosso - SEDUC/CEFAPRO, Sinop, BR
}

\begin{abstract}
RESUMO: Neste artigo apresentamos as políticas públicas de ensino na Educação Básica em Mato Grosso mediante análise documental das Orientações Curriculares para a Educação Básica e das Orientações Curriculares para a Área de Linguagens. Também descrevemos algumas práticas coletivas utilizadas pela Secretaria de Estado de Educação para a elaboração e divulgação das ideias contidas nos documentos até sua chegada às escolas, sobretudo a partir do trabalho realizado pelos Centros de Formação e Atualização dos Profissionais da Educação Básica do Estado de Mato Grosso (CEFAPRO), tomando como base as ações desencadeadas pelos professores formadores que compõe a área de linguagens.

PALAVRAS-CHAVE: políticas públicas; educação básica; orientações curriculares; linguagem.
\end{abstract}

RESUMEN: En este artículo presentamos las políticas públicas de enseñanza en la Educación Básica en Mato Grosso, mediante el análisis documental de las Directrices Curriculares para la Educación Básica y de las Directrices Curriculares para la Área de Linguagens. También describimos algunas prácticas colectivas empleadas por la Secretaría del Estado de la Educación para la elaboración y divulgación de las ideas inscriptas en esos documentos hasta su llegada a las escuelas, sobre todo a partir del trabajo realizado por los Centros de Formación y Actualización de los Profesionales de la Educación Básica del Estado de Mato Grosso (CEFAPRO), basándose en las acciones desencadenadas por profesores formadores que componen el área de lenguajes.

PALABRAS-CLAVE: políticas públicas; educación básica en Brasil; directrices curriculares; lenguaje.

ABSTRACT: This paper presents the public policies of teaching for Basic Education in the state of Mato Grosso, Brazil, through document analysis of two works published, named Curriculum Guidelines for Basic Education and Curriculum Guidelines for Language Area. It also describes some collective practices used by the State Department of Education in order to write and disseminate ideas presented in the documents until they were sent to schools. Especially it discusses , the work done by the CEFAPRO (Center for Training and Professional Upgrading of Basic Education) that belongs to the state of Mato Grosso, based on the actions triggered by professionals who are part of the language area.

KEYWORDS: public policies; Brazilian Basic Education; curriculum guidelines; language.

\section{INTRODUÇÃO}

Em tempos em que se prega um cenário de redemocratização da educação e qualidade de ensino para alcançar a competitividade nacional e mundial, além do desenvolvimento de uma cidadania que capacite o

\footnotetext{
* Este trabalho faz parte de um projeto de pesquisa interinstitucional de pós-doutoramento que envolve professores-formadores-pesquisadores de diferentes instituições de ensino (PUCSP; UNEMAT/Sinop; CEFAPRO/Sinop). Para alcançar os objetivos propostos pelo projeto, fez-se necessário um estudo das Orientações Curriculares, documentos oficiais que norteiam o ensino da Educação Básica em Mato Grosso, para um (re)conhecimento dos pressupostos teóricos que embasam as práticas educativas no Estado.

**E-mail: leandraines@hotmail.com.

****6-mail: rramos1@uol.com.br.

${ }^{1}$ E-mail: cristina.sara.27@hotmail.com.
} 
indivíduo para o mundo globalizado, falar em políticas públicas para a educação é um tema indispensável, uma vez que esta se encontra em acelerado processo de mercantilização.

Das diversas definições e modelos sobre políticas públicas, Souza (2006) extrai e sintetiza alguns elementos principais. Para ela, a política pública: i) permite distinguir entre o que o governo pretende fazer e o que, de fato, faz; ii) envolve vários atores e níveis de decisão, embora seja materializada através dos governos, e não necessariamente se restringe a participantes formais, já que os informais são também importantes; iii) é abrangente e não se limita a leis e regras; iv) é uma ação intencional, com objetivos a serem alcançados; v) embora tenha impactos no curto prazo, é uma política de longo prazo; e, vi) envolve processos subsequentes após sua decisão e proposição, ou seja, implica também implementação, execução e avaliação (SOUZA, 2006, p. 36-37). Ainda consoante essa autora, em uma democracia, definições sobre políticas públicas são uma questão de ação coletiva e de distribuição de bens coletivos e requerem o desenho de incentivos seletivos para diminuir sua captura por grupos ou interesses personalistas (SOUZA, 2006, p. 37).

Conforme pondera Bittencourt (2009), o Brasil, um dos signatários dos documentos consolidados pela Conferência Mundial de Educação para Todos, ocorrida na Tailândia, em 1990 (DECLARAÇÃO, 2012) e pela Cúpula Mundial de Educação para Todos, ocorrida no Senegal, em 2000 (CÚPULA, 2012) - que reafirmam a educação como direito de todos - assumiu "compromissos que irão influenciar as diretrizes e metas das políticas públicas de educação, em específico ao que se refere ao Ensino Fundamental” (p. 43). Nesse sentido, considerando os prós e os contras, o autor assevera que:

Estudos e propostas dos organismos multilaterais, guardadas as devidas peculiaridades de suas prioridades e focos, alcançam convergência quanto à defesa da descentralização como forma de desburocratização do Estado e de abertura a novas formas de gestão da esfera pública; da autonomia gerencial para as unidades escolares e, ainda, a busca de incrementos nos índices de produtividade dos sistemas públicos, acentuadamente marcada pelo viés neoliberal. (BITTENCOURT, 2009, p. 43).

O status que o Estado confere a essas políticas interfere na elaboração e nas dimensões dadas às políticas públicas de educação, embora não caiba somente a ele decidir sem um instrumento de mediação entre sociedade e projeto nacional. Entretanto, é importante se avaliar as propostas de se tentar prover melhorias na qualidade da escola e do ensino público brasileiro, para que essas propostas não se fundamentem em soluções de problemas segmentados e específicos, não representando uma melhoria substantiva e significativa na qualidade da educação.

Bittencourt (2009) nos alerta que as tentativas de reformas educacionais nas últimas décadas apresentam em seu bojo o foco na gestão educacional e na escola, como eixos fundamentais de transformação, concentrando-se em sua autonomia e evidenciando uma mudança radical na forma de pensar e implementar a gestão dos sistemas educacionais. Para ele, tais mudanças visam rearticular o sistema educacional com os sistemas político e produtivo, pois "a era do conhecimento, da globalização dos mercados e do avanço das novas tecnologias gerou a necessidade de ressignificar a organização escolar de modo a tornar a escola eficiente e 'democrática no processo de formação do 'novo cidadão', o cidadão da era globalizada" (BITTENCOURT, 2009, p. 52).

Em nossa atuação nas áreas de formação docente, ensino e aprendizagem de línguas e metodologias de ensino na Educação Básica (EB), bem como na atuação com docentes do ensino público regular, temos percebido que, não raramente, pouco sabem sobre e pouco levam em consideração as políticas públicas que norteiam as ações na EB, principalmente, no conhecimento e acompanhamento daquelas específicas do contexto nas quais os sujeitos estão inseridos. De igual modo, a interlocução com professores em serviço também tem apontado certa ausência de conhecimento e/ou entendimento das concepções teóricas adotadas. Diante deste diagnóstico, acreditamos ser importante o (re)conhecimento das políticas públicas de ensino para a Educação Básica em Mato Grosso, já que influenciam diretamente as práticas em sala de aula nas escolas públicas estaduais, ademais de serem os documentos relativamente novos (2010).

Nesse sentido, a partir de análise documental, o primeiro objetivo deste texto é apresentar uma síntese das concepções teóricas que norteiam as práticas a partir dos documentos chamados Orientações Curriculares para a Educação Básica (2010a), e das Orientações Curriculares para a área de Linguagens (MATO GROSSO, 2010b). O outro objetivo do texto é apresentar as práticas utilizadas pela Secretaria de Estado de Educação (SEDUC) para a elaboração e divulgação das ideias contidas nos documentos até sua chegada às escolas. 
Algumas das etapas descritas no texto têm sido acompanhadas - e de certa forma implementadas - por alguns pesquisadores de nosso grupo de pesquisa (o Grupo de Estudos e Pesquisas em Linguística Aplicada), que agrupa estudiosos da área de linguagens e especificidades² (educação do campo, educação especial, e tecnologias) atuantes em diferentes disciplinas (Língua Portuguesa, Língua Estrangeira, Arte, dentre outras), e provenientes de diferentes instituições de ensino (instituições de ensino superior UNEMAT/Sinop, PUCSP; escolas públicas estaduais e municipais de Sinop; Centro de Formação e Atualização dos Profissionais da Educação Básica/Polo de Sinop).

\section{2 (RE)LEITURAS DOS DOCUMENTOS OFICIAIS}

Dedicamos esta seção para uma breve exposição das principais concepções que norteiam o currículo geral da Educação Básica em Mato Grosso, a partir das Orientações Curriculares para a Educação Básica (MATO GROSSO, 2010a) - doravante OCEB - e das Orientações Curriculares para a área de Linguagens (MATO GROSSO, 2010b), aqui denominadas de OCL. Não nos ateremos, neste momento, a emissão de julgamento quanto às ideias expostas nos documentos, embora corroboremos o pensamento de Pennycook (1994, p. 301) quando afirma que, nas práticas discursivas, nenhum conhecimento é neutro ou apolítico.

\subsection{Orientações Curriculares: contextualização da Educação Básica em Mato Grosso}

As novas determinações do mundo social e produtivo contempladas pela Lei de Diretrizes e Bases da Educação Nacional 9394/96 (LDBEN) apontam para duas linhas epistemológicas que orientam a elaboração das OCEB no Estado de Mato Grosso. De acordo com o documento, a primeira anuncia "metas claras e democraticamente estabelecidas no sentido de orientar a ação política do Estado em todas as instâncias, particularmente no tocante a investimentos" (MATO GROSSO, 2010a, p. 16). A segunda prevê "uma concepção formulada de modo a integrar todos os saberes, articulando formação científica, tecnológica e cultural, com vistas a superar a ruptura historicamente determinada entre uma escola que ensine a pensar através do domínio teórico-metodológico do conhecimento, socialmente produzido e acumulado" (MATO GROSSO, 2010a, p. 16).

As diretrizes tomam como categoria organizadora do processo de sua construção a consideração do trabalho como práxis humana, concebendo o humano por sua capacidade de intervir na natureza e transformá-la em favor da sustentabilidade. Nelas, a educação é conceituada "como elemento propiciador de conhecimento sobre a realidade, pelo debruçar-se sobre ela, a fim de extrair contextos significativos para a formação humana" (MATO GROSSO, 2010a, p. 09). As diretrizes amparam-se nas concepções defendidas por Pistrak (1981), em que o trabalho aparece como princípio educativo. Para esse autor o trabalho é a essência do ser social e está diretamente relacionado à realidade social em um dado momento histórico. Desta forma, o homem se constitui ao transformar a natureza. Sendo assim, o papel da escola será o de preparar o indivíduo para a vida em sociedade, estabelecendo uma relação entre escola, trabalho e realidade social em que esse indivíduo está inserido. Nesta perspectiva o trabalho humano está associado ao estudo da realidade humana.

Antecipando o ensino de nove anos que hoje também é adotado em todo o Brasil, o documento é fruto de propostas educacionais para o ensino fundamental que intencionam superar a escola organizada por séries, norteando sua organização em ciclos de aprendizagem com duração de três anos para cada ciclo. A reorganização do ensino fundamental em ciclos em Mato Grosso teve início logo após a aprovação da LDBEM 9394/96, em 1997, mediante a detecção de vários problemas como, por exemplo, o alto índice de evasão escolar e repetência. Já para o ensino médio, a proposta é a de integração entre trabalho manual e intelectual.

As OCEB adotam uma concepção de educação como totalidade, estabelecendo sua integração e assegurando sua organicidade, e justifica que esta concepção alinha-se à filosofia da Lei de Diretrizes e Bases da Educação Nacional (LDBEN 9394/96) que preconiza, em seu artigo terceiro, os seguintes princípios: "igualdade de condições para o acesso e permanência na escola; liberdade de aprender, ensinar, pesquisar e

\footnotetext{
2 As pesquisadoras que atuam nas especificidades compõem o grupo de estudos devido à formação inicial em Letras e/ou Pedagogia. Especificidades é uma nomenclatura adotada pela SEDUC para a seleção e organização dos professores-formadores para atuação nas escolas do estado por meio do Projeto Sala de Educador, política de formação continuada adotada pela Secretaria.
} 
divulgar a cultura, o pensamento, a arte e o saber; pluralismo de ideias e de concepções pedagógicas; respeito à liberdade e apreço à tolerância; valorização da experiência extraescolar; e vinculação entre a educação escolar, o trabalho e as práticas sociais" (conforme transcrito em MATO GROSSO, 2010a, p. 12). O documento do Estado do Mato Grosso descreve ainda que, na atualidade, há uma necessidade de se reconhecer que o acesso ao conhecimento sistematizado para os filhos daqueles que vivem do trabalho acontece no espaço escolar (2010a, p. 16). Nesse sentido, a proposta político pedagógica da EB para esse estado tem como objetivo:

o domínio intelectual da tecnologia, a partir da cultura, contemplando o currículo de forma teóricoprática em seus fundamentos, bem como os princípios científicos e linguagens das diferentes tecnologias que caracterizam o processo de trabalho contemporâneo, em suas relações com a cultura, considerados sua historicidade. (MATO GROSSO, 2010a, p. 23).

As OCEB trazem em seu bojo fortes críticas, e opõe-se abertamente, à matriz tecnicista de visão positivista que tem dominado a educação no contexto brasileiro. O projeto pedagógico praticado na escola tradicional, chamado por Kuenzer (2000) de taylorista/fordista, evidencia a prática fragmentada que embasa esta visão, atuando como uma das formas da materialização da divisão entre o conhecimento científico e o saber prático, ou seja, "como o espaço por excelência, da distribuição desigual e do acesso ao saber teórico, divorciado da prática, representação abstrata feita pelo pensamento humano, e que corresponde a uma forma peculiar de sistematização do conhecimento, elaborada a partir da cultura da classe dominante" (MATO GROSSO, 2010a, p. 21). O documento preconiza que tal projeto caracteriza-se por centrar-se ora nos conteúdos ora nas atividades, sem, entretanto, propiciar relações entre o aluno e o conhecimento que possam integrar efetivamente conteúdo e método, ou mesmo que se constituam em mediações significativas que se concretizem em aprendizagem. Além desses princípios que norteiam essa pedagogia, destacam-se também a memorização através da repetição, e a ênfase nas dimensões psicomotoras e cognitivas, ou seja, no desenvolvimento de capacidades lógico-formais, sem a consideração da dimensão afetiva, ou comportamental (MATO GROSSO, 2010a, p. 25 e 28).

Uma vez que mudanças na sociedade demandam mudanças no perfil dos indivíduos que a compõem, o documento assevera que as mudanças ocorridas na contemporaneidade sugerem a construção de um Projeto Político Pedagógico diferenciado e que leve em consideração àquelas ocorridas no mundo do trabalho, uma vez que exigem um novo tipo de intelectual. Este novo tipo de intelectual não consegue se formar, entretanto, pela pedagogia nascida das formas tradicionais de organização e gestão da vida social e produtiva. As OCEB asseguram que uma de suas finalidades é, pois, enfrentar a necessidade mister de reformulação do projeto escolar.

A concepção de totalidade, marcada pelo materialismo histórico-dialético, cujos eixos estruturantes são o conhecimento, o trabalho e a cultura, é defendida no documento e não pretende desconsiderar os princípios acima mencionados, mas, sim, rearticulá-los em uma concepção que tome o processo educativo a partir de uma concepção histórica de homem em sua integralidade, que o compreenda como síntese do desenvolvimento social e individual. Para tanto, o indivíduo precisa aprender a relacionar-se "com o conhecimento de forma ativa, construtiva e criadora” (MATO GROSSO, 2010a, p. 29). Ecoando pressupostos teóricos defendidos por Vygotsky (1984), isso será possível mediante o domínio de diferentes linguagens, já que a relação entre o homem e o conhecimento dá-se pela mediação destas linguagens, além do desenvolvimento do "raciocínio lógico e da capacidade de usar conhecimentos científicos, tecnológicos, sócio-históricos e culturais para compreender e intervir na vida social e produtiva” (MATO GROSSO, 2010a, p. 28).

Assim, a concepção metodológica impressa no documento compreende o processo de produção do conhecimento como resultante da relação entre o homem e as relações sociais em seu conjunto, através da atividade humana e a concepção epistemológica, por sua vez, rejeita tanto o entendimento que o conhecimento se produz através da mera contemplação, como o entendimento de que o conhecimento é mero produto de uma consciência que pensa a realidade, mas não nela e a partir dela, porém metafisicamente elaborada. Consoante o documento, para a elaboração do Projeto Político Pedagógico (PPP), as escolas precisam considerar alguns pressupostos acerca do conhecimento. O quadro 01 sintetiza esses seis pressupostos descritos nas OCEB. 
Quadro 01 - Síntese dos pressupostos acerca do conhecimento a serem considerados na elaboração do PPP conforme proposição das OCEB

1. O conhecimento é fruto da atividade humana, compreendida em sua dimensão práxica, resultante da articulação entre sujeito e objeto, pensamento e ação, teoria e prática, homem e sociedade;

2. O conhecimento é a compreensão das leis que regem os fenômenos, não apenas em um dado momento, mas no movimento de sua transformação;

3. O Conhecimento de fatos ou fenômenos é o conhecimento do lugar que eles ocupam na totalidade concreta;

4. O conhecimento é produzido ou apropriado através do pensamento que se move do mais simples para o mais complexo, do imediato para o mediato, do conhecido para o desconhecido e de uma visão confusa e sincrética do todo para o conhecimento mais profundo e substancial dos fenômenos da realidade que ultrapassa a aparência para deixar ver as conexões, as relações internas, as dimensões estruturais e formas de funcionamento, no sentido da aproximação da verdade;

5. O conhecimento exige o desenvolvimento da capacidade de construir o caminho metodológico através da compreensão da relação entre concreto e abstrato e entre lógico e histórico;

6. O conhecimento deverá promover a passagem da aceitação da autoridade para a autonomia, na perspectiva da autonomia ética, permitindo que o sujeito avance para além dos moldes sociais em suas atividades, criando novas possibilidades fundadas em sólidos argumentos, sem ferir as constrições sociais necessárias à vida coletiva.

Fonte: Mato Grosso (2010a, p. 33 a 35 - trechos extraídos diretamente do documento).

Para superar a fragmentação já mencionada, rumo à construção da totalidade, e ainda explicitando sua concepção metodológica, amparado nos estudos de Machado (1995), o documento preconiza um trabalho transdisciplinar, que demanda conhecimento disciplinar, evidenciando interdependência, compreendido como "rearticulação do conhecido" (MATO GROSSO, 2010a, p. 36). Quanto ao tratamento metodológico, em súmula as OCEB asseveram que este:

tem seu fundamento na concepção de práxis, que se constitui no movimento através do qual o homem e todos os homens, no trabalho, ao articular reflexão e ação, teoria e prática, transitam do senso comum ao conhecimento científico e assim transformam a realidade, produzem sua consciência e fazem a história. (MATO GROSSO, 2010a, p. 42).

Fica visível o papel de mediador requerido ao docente e a busca de construção de autonomia por parte do aluno. Amparando-se na corrente sócio-histórica de base vygotskiana, os processos pedagógicos são definidos como intencionais e deliberados, tendo por objetivo promover relações significativas entre o aprendiz e o conhecimento produzido pelos homens em seu processo social e histórico, criando as condições materiais de existência desse conhecimento.

Com base em Azevedo (2007), as OCEB pretendem resgatar os princípios humanizadores da educação e, com esta concepção, a organização do ensino no estado faz-se através dos ciclos de formação humana. Para alcançar tais princípios, fundamentado nos pressupostos delineados por Brandão (2002), o documento argumenta ser necessário capturar as questões das comunidades, objetivando integrá-las no currículo. Para tanto, definem como essenciais os mecanismos da investigação socioantropológica e do complexo temático.

Nessa perspectiva, as OCEB afirmam que a escola por ciclos de formação, diferente da seriação, "procura adaptar-se aos ciclos da vida, às fases do desenvolvimento humano" e tal organização desencadeia o que os documentos denominam de "processo de enturmação por idade" (MATO GROSSO, 2010a, p. 56). Preconizam, também, a criação de novos espaços "para garantir o tempo de aprendizagem para todos", como as "turmas de superação", sob os cuidados de um profissional denominado "Professor Articulador" e "Sala de Recursos", para alunos cuja avaliação aponte para uma necessidade de "atendimento especial, individualizado" (MATO GROSSO, 2010a, p. 59).

No que diz respeito à avaliação, corroborando o pensamento de Rocha (1996, p. 52, citado em MATO GROSSO, 2010a, p. 61), o documento a define "como práxis emancipatória" e a considera "um processo contínuo, participativo, com função diagnóstica, prognóstica e investigativa”. Os registros da produção do aluno são feitos por meio de relatórios individuais, sob o "conceito de aprendizagem para todos, como finalidade e obrigação da escola e direito do educando" e não com "o conceito de reprovação/aprovação", já que o documento o considera como "fator de exclusão" (MATO GROSSO, 2010a, p. 62). 
Sintetizando, podemos dizer que as bases teóricas que norteiam as políticas públicas de ensino na EB em Mato Grosso são fundamentadas, principalmente, nos seguintes autores/pensadores e aspectos teóricos deles provenientes, demonstrando que os documentos congregam uma pluralidade de pressupostos:

a) O cientista político Antônio Gramsci $(1978,1988)$ atenta para múltiplas formas e possibilidades de organização da educação na concepção de escola única (MATO GROSSO, 2010a, p. 18).

b) O educador e filósofo Paulo Freire (1994) observa que a produção do conhecimento se dá no processo de criticização, sendo este o desafio do educador (MATO GROSSO, 2010a, p. 48).

c) O educador Moisey Pistrak (1981) orienta a concepção curricular organizada pelo complexo temático e a formação de cidadãos ativos ao considerar "que o objetivo da escola é a compreensão crítica e dialética da realidade, na qual os temas e fenômenos estudados estão articulados entre si e com a realidade macrossocial e universal" (MATO GROSSO, 2010a, p. $54)$.

d) O psicólogo Lev Vygotsky (1984) subsidia a visão do papel do professor e do aluno como sujeitos ativos no processo de construção do conhecimento no social.

e) O filósofo, médico, político e psicólogo Henri Wallon (1998) aponta para os aspectos emocionais relevantes na organização dos ciclos de formação humana, regime escolar adotado em Mato Grosso, atentando para o "reconhecimento da criança nas suas diferentes idades e em situações diferenciadas" (MATO GROSSO, 2010a, p. 57).

f) O filósofo epistemólogo Jean Piaget (cf.: LA TAYLE, 1992) fundamenta os ciclos de formação humana a partir das fases de desenvolvimento da criança e caracteriza o processo denominado de enturmação.

\subsection{Orientações Curriculares: Área de Linguagens}

Considerando todos os pressupostos já descritos anteriormente acerca das OCEB, para as OCL de Mato Grosso "as linguagens são construídas historicamente na interação social" que "envolve indivíduo, história, cultura e sociedade em uma relação dinâmica entre produção, circulação e recepção". A linguagem é, pois, compreendida pelos documentos "como o espaço de interlocução da atividade sociointeracional e possibilita reafirmar as práticas sociais de linguagem constituídas pela/na inter e transdisciplinaridade" (MATO GROSSO, 2010b, p. 11). Desta forma o currículo da área é constituído, nas OCL, pelas disciplinas de Arte, Educação Física, Língua Estrangeira Moderna (Língua Inglesa e Língua Espanhola) e Língua Portuguesa, as quais são trabalhadas através do que são descritos como "objetos comuns", a saber, "o código, o texto e a leitura”, que formam o campo conceitual da área (MATO GROSSO, 2010b, p. 12).

As OCL apóiam-se teoricamente na concepção de linguagem presente nos Parâmetros Curriculares Nacionais (BRASIL, 1998) e, portanto, a descrevem como construída historicamente em situação de interação social, levando-se, além disso, que ela "considera o contexto, as intenções estratégias e recursos usados tanto na produção oral e escrita e que admite uma multiplicidade de posicionamentos diferentes colocados em diálogo e interação" (MATO GROSSO, 2010b, p. 63). Esta visão encontra eco nas ideias de Vygotsky (1984) de que a linguagem estabelece mediações entre o estudante e o conhecimento de todas as áreas, bem como entre a situação na qual o conhecimento é produzido e suas novas formas de utilização na prática.

Nesse sentido, Bakhtin (2003) também explicita que o emprego da língua efetua-se em forma de enunciados, quer sejam orais ou escritos, concretos e únicos, proferidos pelos integrantes desse ou daquele campo da atividade humana. Esses enunciados refletem as condições específicas e as finalidades de cada um dos referidos campos não só por seu conteúdo temático e pelo estilo da linguagem, ou seja, pela seleção dos recursos lexicais, fraseológicos e gramaticais da língua, mas, acima de tudo, por suas construções composicionais (BAKHTIN, 2003, p. 261-262).

A concepção de Linguagem apresentada nas OCL (MATO GROSSO, 2010b) caracteriza-se por integrar disciplinas que apresentam princípios, conceitos, modelos interpretativos e explicativos em comum sobre

${ }^{3}$ Sobre Wallon, conferir também: Galvão (1998). 
certos aspectos do mundo. Em consonância com esta visão de linguagem, Bourdieu (1991, p. 107), argumenta:

Quando se focaliza a linguagem como objeto autônomo, aceitando a separação radical que Saussure fez entre linguística interna e externa, entre ciência da linguagem e ciência dos usos sociais da linguagem, se está condenando a olhar dentro das palavras para o poder das palavras, isto é, procurando por ele onde não será encontrado.

Dessa forma, a proposição para o trabalho por área de conhecimento da linguagem leva em consideração a não dicotomia entre linguagem e usos sociais da linguagem numa perspectiva inter/transdisciplinar, compreendida de forma contextualizada, partindo-se de seus respectivos usos sociais. Em consonância com este pensamento, Rajagopalan (2003) ao falar sobre o momento de revisão epistemológica que perpassa o trabalho com a linguagem na contemporaneidade, delineia que se esta é uma prática social, ao estudá-la, consequentemente, estudamos a sociedade e a cultura das quais ela é parte constituinte e constitutiva. Esta nova proposição de trabalho lança o desafio de se compreender como esse trabalho acontecerá na atualidade e em que contexto os profissionais podem realinhá-lo, de forma a garantir que haja a prática inter/transdisciplinar proposta pelos documentos oficiais quer os da esfera federal quer os da estadual.

Ao trabalhar a linguagem como prática social, está sendo contemplada a proposta presente nas OCL, que orientam que o trabalho educativo deva partir da articulação dos eixos estruturantes "conhecimento, trabalho e cultura" (MATO GROSSO, 2010b, p. 07). Em conformidade com esses eixos estruturantes, as OCL apresentam os eixos articuladores da área para o ensino fundamental, quais sejam: "Linguagens e processos de interação, representação, leitura e prática; Apropriação dos sistemas de representação das Linguagens; e Formação sociocultural nas diferentes linguagens" (MATO GROSSO, 2010b, p. 08).

As diretrizes asseveram que os eixos articuladores são fundamentais no processo de ensino e aprendizagem, e que precisam ser coordenados e articulados entre si, pois é através desta articulação que cada área de conhecimento organiza e elabora suas ações em conformidade e a partir da realidade local, na tentativa de assegurar um aprendizado contextualizado e significativo, para que não haja a dicotomia entre aprendizagem na escola e no mundo exterior.

São esses eixos também que possibilitam o desenvolvimento das capacidades "cognitivas, procedimentais e atitudinais". $\mathrm{Na}$ perspectiva vygotskiana, adotada no documento, as capacidades "referem-se ao conhecimento e aplicação de estratégias e técnicas apropriadas relacionadas aos conteúdos aprendidos, que o aluno busca, em suas experiências anteriores, para analisar e resolver novos problemas" (MATO GROSSO, 2010b, p. 8). Essas capacidades são construídas pelos aprendizes através das relações que estabelecem entre si, com o outro, com o conhecimento e com o contexto sociocultural.

Desta forma, tais capacidades serão desenvolvidas durante toda a EB, sendo que ganharão abrangência e aprofundamento de acordo com o desenvolvimento cognitivo, com o processo de aprendizagem e autonomia de cada estudante. Isso será observado através do que as OCL denominam de "descritores"; ou seja, são eles que evidenciarão a construção e o desenvolvimento das capacidades, já que "traduzem o diagnóstico da realidade no decorrer do processo de desenvolvimento e aprendizagem” (MATO GROSSO, 2010b, p. 10), bem como são subsídios para os educadores planejarem e intervirem quanto às necessidades dos estudantes.

No quadro 02 (abaixo), sistematizamos as capacidades, descritas no documento, a serem desenvolvidas com a mediação do professor e dos pares, em articulação com o meio físico e social, para cada Ciclo de Formação Humana. A sistematização nos permite inferir que, para o terceiro ciclo, as capacidades são praticamente as mesmas previstas para o segundo ciclo, porém o grau de dificuldade é mais profundo.

O documento assevera que as atividades devem "oportunizar situações desafiadoras para que os (as) estudantes desenvolvam sua capacidade de pensar, organizar as informações que recebem compreendendo o seu sentido e atribuir significados que ampliam o processo de letramento" (MATO GROSSO, 2010b, p. 22), elaborando e sistematizando os conhecimentos de forma intencional no processo ensino aprendizagem.

Ao tratar o processo ensino-aprendizagem por área de conhecimento e desenvolvimento de capacidades, e em uma perspectiva sociocultural vygotskiana, o professor é visto, nos documentos, como mediador da aprendizagem. Espera-se que ele oportunize aos alunos, por meio de diferentes situações de aprendizagem, "compreender as relações socioculturais e ambientais em que estão envolvidos" (MATO GROSSO, 2010b, 
p. 35), mediante o planejamento coletivo das ações pedagógicas. Acreditamos, pois, que este é um dos grandes desafios que está posto para os profissionais da educação em Mato Grosso, primeiramente no sentido de compreender as bases teóricas e, posteriormente, no seu desenvolvimento, efetivamente, na prática, no chão da escola, conforme palavras de Nóvoa (2009).

Quadro 02 - Capacidades a serem desenvolvidas nos Ciclos de Formação Humana de acordo com as OCL

\begin{tabular}{|c|c|c|}
\hline Primeiro Ciclo & Segundo Ciclo & Terceiro Ciclo \\
\hline $\begin{array}{l}\text { Reconhecer as linguagens } \\
\text { como elementos integradores } \\
\text { dos sistemas de comunicação; } \\
\text { - Ler, compreender e construir } \\
\text { diferentes textos; } \\
\text { - Codificar e decodificar } \\
\text { Linguagens; } \\
\text { - Fazer uso social das diversas } \\
\text { linguagens em diferentes } \\
\text { situações de fruição e } \\
\text { interação; } \\
\text { - Vivenciar as diversas práticas } \\
\text { de Linguagens; } \\
\text { - Compreender as manifestações } \\
\text { das Linguagens; } \\
\text { Valorizar a diversidade } \\
\text { manifestada nas diferentes } \\
\text { linguagens. }\end{array}$ & $\begin{array}{l}\text { - Fazer uso das linguagens } \\
\text { como elementos } \\
\text { integradores dos sistemas } \\
\text { de comunicação; } \\
\text { - } \quad \begin{array}{l}\text { Ler, compreender e } \\
\text { construir diferentes textos; }\end{array} \\
\text { - } \quad \begin{array}{l}\text { Codificar e decodificar } \\
\text { sistemas das diferentes } \\
\text { linguagens; }\end{array} \\
\text { - } \quad \begin{array}{l}\text { Fazer uso social das } \\
\text { diversas linguagens em } \\
\text { diferentes situações de } \\
\text { fruição e interação; }\end{array} \\
\text { - Ressignificar as diversas } \\
\text { práticas de linguagens; } \\
\text { - Compreender e valorizar a } \\
\text { diversidade manifestada nas } \\
\text { diferentes linguagens. }\end{array}$ & $\begin{array}{l}\text { - Compreender e utilizar as } \\
\text { linguagens; } \\
\text { - Ler compreender e } \\
\text { construir diferentes textos, } \\
\text { considerando as condições } \\
\text { de produção, recepção e } \\
\text { circulação; } \\
\text { - Codificar, decodificar e } \\
\text { ressignificar sistemas das } \\
\text { diferentes linguagens; } \\
\text { - Fazer uso social das } \\
\text { diversas linguagens em } \\
\text { diferentes situações de } \\
\text { fruição e interação; } \\
\text { - Vivenciar e ressignificar as } \\
\text { diversas práticas de } \\
\text { linguagens; } \\
\text { Compreender e valorizar a } \\
\text { diversidade manifestada } \\
\text { nas diferentes linguagens. }\end{array}$ \\
\hline
\end{tabular}

Fonte: Mato Grosso (2010b, p. 23 a 25; 32 a 34; 47 a 53 - trechos extraídos do documento).

Considerando que o Ensino Médio será a última etapa da EB, os pressupostos teóricos e metodológicos para o trabalho com a linguagem será o mesmo, na perspectiva de formação humana, tendo como principal função "tornar a experiência escolar uma vivência em que o estudante possa compreender e usar as diferentes linguagens" (MATO GROSSO, 2010b, p. 65). O documento aborda, pelo menos, cinco objetivos comuns que podem ser trabalhados de forma interdisciplinar:

a) ler e interpretar diferentes linguagens;

b) fazer uso da expressão oral na exposição de ideias, pontos de vista e argumentos;

c) analisar fatos e ideias constantes da realidade, estabelecendo relações e formulando hipóteses;

d) interpretar os recursos expressivos das diferentes linguagens relacionando textos e seus contextos de acordo com as condições e razões de sua produção;

e) produzir textos nas diferentes linguagens, visando organizar e registrar informações para expressão e comunicação em situações que exijam maior formalidade. (MATO GROSSO, 2010b, p. 65).

Percebe-se, então, que o trabalho com a linguagem nessa concepção extrapola a leitura e a escrita de textos, pois através da linguagem como prática social é que o estudante poderá situar-se, compreender-se e compreender o mundo que o cerca e nele agir. 
A possibilidade de trabalhar a linguagem de forma mais abrangente e coletivamente tem motivado muitos profissionais da educação a rever suas práticas anteriormente fragmentadas e buscar, sobretudo através da Formação Continuada, novas formas de atuação.

\section{A PRÁticA: ENTRE A COMPREENSÃo DAS CONCEPÇÕES DO CURRÍCULO E SUA IMPLANTAÇÃO NAS ESCOLAS}

Para a SEDUC, o surgimento das OCEB se fundamenta na "decisão política de fazer chegar ao chão da escola um texto claro e conciso que, a par dessa clareza e concisão, ofereça ao professor uma visão inequívoca do homem e da sociedade que se quer formar" (MATO GROSSO, 2010a, p. 07). Essa visão se embasa nos avanços de documentos como a LDBEN (1996) que, por exemplo, permitem uma gestão compartilhada de educação.

O documento foi construído ao longo de mais de uma década, mediante estreito diálogo entre diferentes instituições como o Ministério da Educação e Cultura, as Universidades Públicas, o Conselho Estadual de Educação, o Sindicato dos Trabalhadores na Educação Pública, dentre outras entidades. Assim, caracterizase como construção coletiva e democrática em que todos os profissionais tiveram a possibilidade de participar das discussões e apresentar sugestões que fomentaram sua construção. Além deste momento coletivo a SEDUC também se comprometeu com a divulgação e consolidação das OCEB por meio de formação continuada aos profissionais, uma vez que essas formações norteiam (ou deveriam nortear) os Projetos Políticos Pedagógicos das escolas.

Os Centros de Formação e Atualização dos Profissionais da Educação Básica do Estado de Mato Grosso (CEFAPRO) são unidades administrativas da SEDUC e têm papel importante como agentes executores da política de formação continuada dos profissionais da educação básica da rede pública de ensino (ver figura 01, abaixo, referente ao mapa dos CEFAPROs em Mato Grosso). Atualmente são quinze os CEFAPROs em funcionamento em cidades-polo, que estão estrategicamente localizados para atender as escolas e que atuam com a concepção de trabalho em rede. Dentre os cargos exercidos pela equipe de cada CEFAPRO, existem os professores formadores que mediam as ações e atuam organizados por áreas" (MATO GROSSO, 2010c).

Assim, houve aproximadamente dois anos de estudos do texto preliminar nas escolas, acompanhados pelo CEFAPRO/SEDUC; entre os dias 03 a 06 de agosto de 2010, por exemplo, a equipe do CEFAPRO/Polo de Sinop esteve reunida e foram sistematizadas as sugestões dos profissionais das escolas dessa região para o texto que serviu de orientação para a atuação docente no Estado. Na ocasião, estavam presentes gestores da SEDUC e profissionais das escolas do polo representando todas as áreas, bem como as especificidades; muitas sugestões foram expressas e posteriormente sistematizadas pelos formadores do CEFAPRO e encaminhadas à SEDUC para apreciação junto aos demais polos que, por sua vez, fizeram este mesmo processo para a construção do documento.

Nos anos de 2010 e 2011, muitas dúvidas sobre as OCEB foram sanadas no desenvolvimento do Projeto Sala de Educador, que é o projeto de formação continuada desenvolvido nas escolas estaduais matogrossenses, assegurado pelas políticas públicas de formação dos profissionais da educação básica (MATO GROSSO, 2010c); e também foram organizados eventos pontuais. No ano de 2011, cada CEFAPRO organizou seminários em seus respectivos polos para a implementação das OCEB.

No polo de Sinop, foi realizado, entre 18 a 20 de abril daquele ano, o Seminário das Orientações Curriculares, com o objetivo de propiciar e fomentar, a partir de debates e leituras, a implementação das Orientações Curriculares para a Educação Básica do Estado de Mato Grosso nas escolas do polo de Sinop. Dentre as atividades realizadas, ocorreram a contextualização das orientações, a apresentação da estrutura do documento na área, atividades práticas com os eixos articuladores, capacidades, descritores e objetivos, sistematização da área e, por fim, a socialização no coletivo e avaliação do seminário. Alguns municípios que não puderam participar dos seminários foram contemplados com a formação do CEFAPRO de forma individualizada.

${ }^{4}$ As áreas definidas pela SEDUC são: Linguagens; Ciências Humanas; Ciências da Natureza e Matemática. 
Figura 01 - Mapa dos

CEFAPROs/MT

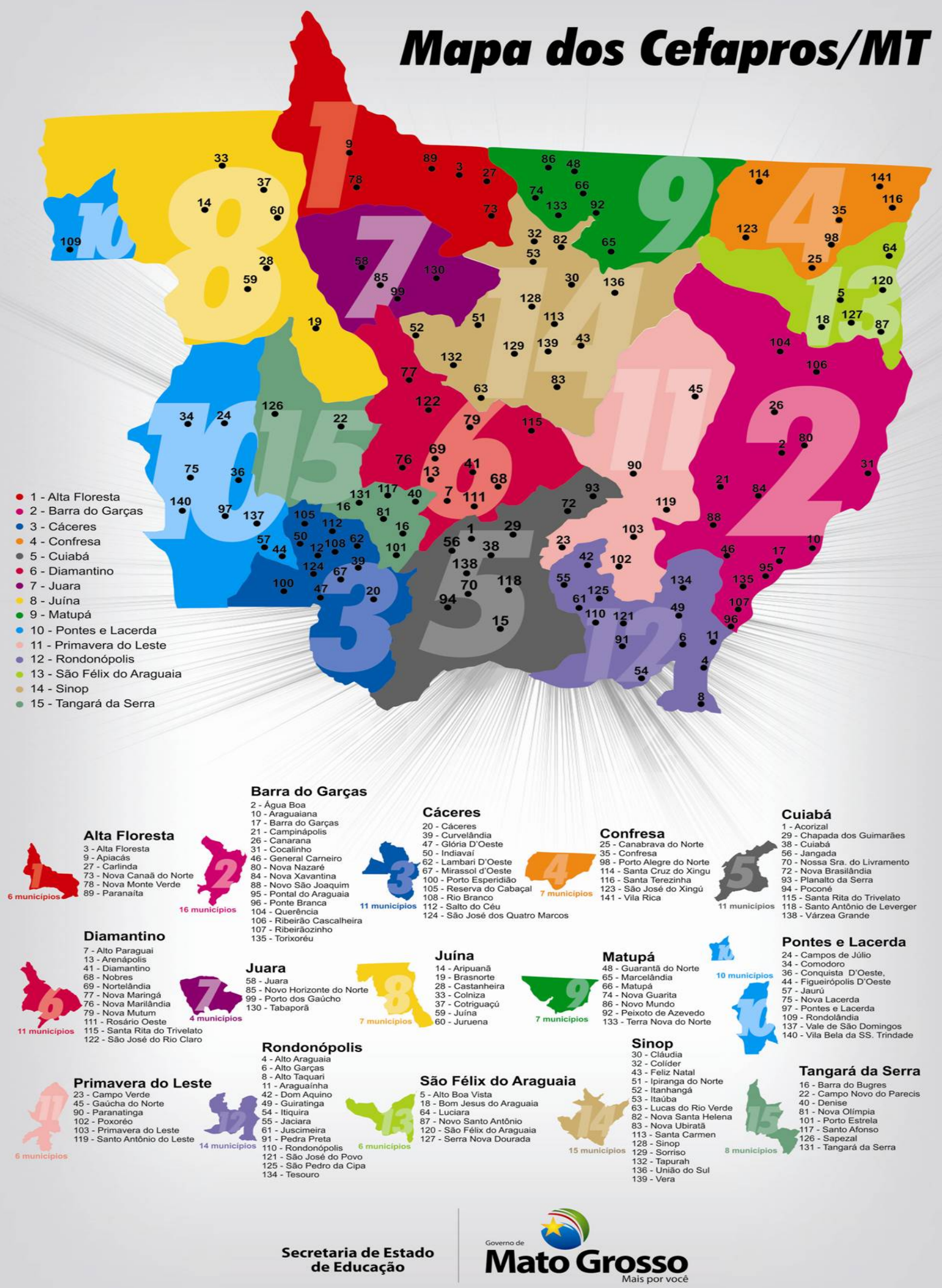

Fonte: http://www.seduc.mt.gov.br/conteudo.php?sid=79\&parent=15\#. 
Em 2012, as escolas receberam da SEDUC um kit contendo os seguintes livros: Orientações Curriculares para a Educação Básica (Concepções); Área de Linguagens; Ciências Humanas; Ciências da Natureza e Matemática; e, Orientações Curriculares das Diversidades (Direitos Humanos, Gênero, Educação Ambiental, Campo, Quilombola, Indígena). Esses documentos também estão disponíveis em formato digital na página da SEDUC ${ }^{5}$ para que cada educador tenha acesso sempre que necessário.

Considerando-se que desde 2009 a SEDUC, os CEFAPROS e as mais de 700 escolas estaduais, através da formação continuada, estabeleceram um diálogo que resultou na construção coletiva destes importantes documentos, cuja dinâmica do processo envolveu encontros nas escolas, encontros municipais, encontros regionais e por fim encontros estaduais, o CEFAPRO/Sinop ainda organizou e desenvolveu nos dias 27 a 30 de agosto de 2012 o Seminário Formação em Rede: Orientações Curriculares para a Educação Básica do Estado de Mato Grosso. Profissionais de 15 municípios que compõe este polo (Cláudia, Colíder, Feliz Natal, Ipiranga do Norte, Itaúba, Itanhangá, Lucas do Rio Verde, Nova Ubiratã, Santa Carmem, Sorriso, União do Sul, Tapurah, Vera, e Sinop) participaram do evento que teve como objetivo principal contribuir com a reconstrução curricular das escolas de modo a considerar as experiências vividas pela/na comunidade escolar, visando o replanejamento do trabalho pedagógico na perspectiva interdisciplinar.

Os temas abordados no evento foram: o materialismo histórico dialético e a educação; o ciclo de formação humana e a sensibilidade do educador; orientações curriculares de Mato Grosso e a democratização da educação; as ações pedagógicas orientadas pelos eixos estruturantes; repensando o currículo na organização do trabalho pedagógico; complexo temático como ferramenta organizadora do currículo; e, as contribuições da pesquisa socioantropológica na escola.

Foram desenvolvidas também sete oficinas com a finalidade de demonstrar como os currículos poderão ser reorganizados nas escolas através do complexo temático a partir do levantamento socioantropológico. No último dia do evento os profissionais participantes socializaram as experiências realizadas nas oficinas, bem como esclareceram dúvidas.

Como resultado desse momento, os profissionais participantes avaliaram que o trabalho através de uma concepção de educação pautada pela formação humana ainda é um desafio, embora percebam que essas transformações são necessárias no fazer pedagógico, tendo em vista as atuais transformações sociais. Já os palestrantes convidados asseveraram que a insatisfação com a escola e com a sociedade que temos nos motiva a buscar entender a concepção de homem e de sociedade proposta pelas OCEB, relembrando a luta de Paulo Freire e outros intelectuais pela humanização da educação. Acreditamos que este é o papel da educação: buscar nas contradições e na construção coletiva uma forma diferente de vivenciar a educação e transformar a realidade social que se nos apresenta. É fato, entretanto, que, para isso, é necessário que haja um redimensionamento e reposicionamento do educador que, com pequenos gestos e pequenas atitudes, precisará fazer surgir um novo fazer transformador e inclusivo, e este é um outro aspecto que ainda se apresenta desafiador para os participantes. Contudo, expressam certa clareza de que, para tal propósito, o diálogo entre as diferentes fontes do conhecimento fortalecerá essas ações. Reconhecem, também, que as angústias dos educadores são salutares, pois demonstram a predisposição dos mesmos à mudança.

Assim, as contribuições da pesquisa socioantropológica na escola poderão propiciar um olhar para a realidade das comunidades escolares e será um ponto de partida para reorganização dos currículos escolares a partir dos complexos temáticos propostos por Pistrak (1981), em que cada instituição escolar terá em seu currículo sua identidade, bem como suas necessidades formativas contempladas, legitimadas pelos Projetos Políticos Pedagógicos de cada instituição escolar.

\section{CONSIDERAÇÕES FINAIS}

Para uma melhor compreensão do processo prático de implantação do currículo baseado nas Orientações Curriculares, descrevemos algumas etapas que julgamos importantes e que acontecem(ram) isolada e/ou concomitantemente. Expomos como foi a construção coletiva das OCEB em Mato Grosso; apresentamos como ocorreu/ocorre sua divulgação nas escolas; discorremos acerca da formação de formadores e dos

5 Disponíveis no sítio: http://www.seduc.mt.gov.br/conteudo.php?sid=463\&parent=9909. 
encontros regionais para capacitação, e como tem acontecido a disseminação da teoria e como deverá acontecer a elaboração coletiva dos currículos nas escolas, que é etapa mais recente.

No que diz respeito às OCL, pontuamos que o trabalho por área de conhecimento da linguagem, em uma perspectiva inter/transdisciplinar, leva em consideração a não dicotomia entre linguagem e seus usos sociais, e que esse trabalho deve partir da articulação dos eixos estruturantes determinados nas OCEB, em conformidade com os eixos articuladores da área. Descrevemos, ainda, que o desenvolvimento dos referidos eixos visam possibilitar o desenvolvimento de capacidades cognitivas, procedimentais e atitudinais.

Como bem afirma Bittencourt (2009, p. 44), "o processo de definição de políticas públicas para uma sociedade reflete os conflitos de interesses, os arranjos feitos nas esferas de poder que perpassam as instituições do Estado e da sociedade como um todo", e em Mato Grosso não é diferente. Na esfera educacional percebemos que não há consenso quanto às políticas delineadas que, teoricamente, tiveram a participação de todos. Muitos docentes mantêm uma postura contrária às bases teóricas e práticas definidas pelo governo, não concordando, por exemplo, com uma escola organizada por ciclos de formação humana e com um currículo baseado em eixos estruturantes. Estas são questões que estão sendo estudadas pela equipe de pesquisadores do GEPLIA e serão temas de futuros textos.

Amparadas em Souza (2006), podemos afirmar que há um conflito nos discursos e nas práticas entre o governo e os profissionais da educação básica, já que o primeiro tem engendrado esforços para a implantação de uma nova política educacional à qual os segundos não são totalmente favoráveis. Vimos no item 3 deste texto que o governo tem realizado diversas ações para a concretização das políticas, tidas como ações intencionais, com objetivos e metas a serem alcançados. Também evidenciamos que houve interesse por parte do governo em envolver vários atores e níveis de decisão, sobretudo no decorrer da década em que se buscou criar bases teóricas, com parceria de diferentes instituições educativas, para a construção, dita coletiva, dos documentos. As diretrizes são abrangentes e não se limitam a regras, mas, sim, procuram criar parâmetros para o desenvolvimento da educação em Mato Grosso, criando espaço para as peculiaridades dos diferentes contextos.

Parece-nos haver uma preocupação por parte do governo mato-grossense, por meio da SEDUC, e mais precisamente do CEFAPRO, em divulgar e garantir a implantação das políticas públicas. Nesse sentido, os CEFAPRO têm sido um dos maiores responsáveis pela sua propagação.

As Orientações Curriculares para a educação básica em Mato Grosso preconizam o desafio da realização de um trabalho coletivo tanto de formação continuada quanto de planejamento e desenvolvimento de atividades. Embora seja possível observar alguns desafios na educação no estado, como o próprio desafio da implementação das OCEB, a reconfiguração das práticas educativas, e a consolidação do Projeto "Sala de Educador", compreendemos que haverá avanços a longo prazo. Ademais, analisando os documentos a que tivemos acesso, percebe-se um movimento de revisão constante, bem como de avaliação dos resultados obtidos até o momento.

\section{REFERÊNCIAS}

AZEVEDO, J. C. Reconversão cultural da escola: mercoescola e escola cidadã. Porto Alegre: Sulina, 2007.

AZEVEDO, J. M. L. A educação como política pública. 3. ed. Campinas, SP: Autores Associados, 2004.

BAKHTIN, M. Estética da criação verbal. São Paulo: Martins Fontes, 2003.

BITTENCOURT, E. S. Políticas públicas para a educação básica no Brasil, descentralização e controle social: limites e perspectivas. 2009. Dissertação (Mestrado em Políticas Públicas e Formação Humana) - UERJ, Rio de Janeiro, RJ.

BOURDIEU, P. Language and symbolic power. Oxford: Polity Press, 1991.

BRANDÃO, C. R. A educação popular na escola cidadã. Petrópolis: Vozes, 2002.

BRASIL. Parâmetros Curriculares Nacionais: $5^{a}$ à $8^{a}$ séries. Ministério da Educação e do Desporto. Secretaria de Educação Fundamental. Brasília, DF: MEC, 1998. 
CÚPULA MUNDIAL DE EDUCAÇÃO. Educação para todos: atingindo nossos compromissos coletivos. Dakar, Senegal, 2000. Disponível em: http://www.oei.es/quipu/marco_dakar_portugues.pdf. Acesso em: 10 out. 2012.

DECLARAÇÃO MUNDIAL SOBRE EDUCAÇÃO PARA TODOS: satisfação das necessidades básicas de aprendizagem. Tailândia, Jomtien, 1990. Disponível em:

http://unesdoc.unesco.org/images/0008/000862/086291por.pdf. Acesso em: 10 out. 2012.

FREIRE, Paulo. Educação como prática da liberdade. 22. reimpressão. São Paulo: Paz e Terra, 1994.

GALVÃO, I. Henry Wallon: uma concepção dialética do desenvolvimento infantil. 4. ed. Petrópolis, RJ: Vozes, 1998.

GRAMSCI, A. Maquiavel, a política e o estado moderno. Rio de Janeiro: Civilização Brasileira, 1988. Os intelectuais e a organização da cultura. Rio de Janeiro: Civilização Brasileira, 1978.

KUENZER, A. Z. Ensino Médio: construindo uma proposta para os que vivem do trabalho. São Paulo: Cortez, 2000.

LA TAYLE, Y. et al (Org.). Piaget, Vygotsky, Wallon: teorias psicogenéticas em discussão. São Paulo: Summus, 1992.

MACHADO, N. J. Epistemologia e didática: as concepções de conhecimento e inteligência e a prática docente. São Paulo: Cortez, 1995.

MATO GROSSO. Orientações Curriculares: concepções para a Educação Básica. Cuiabá, MT: SEDUC/MT, 2010a. 128p.

$126 \mathrm{p}$.

Orientações Curriculares: área de linguagens - Educação Básica. Cuiabá, MT: SEDUC/MT, 2010 b.

Política de formação dos profissionais da Educação Básica de Mato Grosso: formação em rede entrelaçando saberes. Cuiabá, MT: SUFP/SEDUC/MT, 2010c.

NÓVOA, A. Professores: imagens do futuro presente. Lisboa: Educa, 2009.

PENNYCOOK, A. The cultural politics of an international language. London; New York: Longman, 1994.

PISTRAK, M. M. Fundamentos da escola do trabalho. Tradução Daniel Aarão Reis Filho. São Paulo: editora Brasiliense, 1981.

RAJAGOPALAN, K. Por uma linguística crítica: linguagem, identidade e a questão ética. São Paulo: Parábola Editorial, 2003.

ROCHA, S. (Org.). Ciclos de formação: a proposta político-pedagógica da escola cidadã. Cadernos pedagógicos, Porto Alegre: SMED, n. 9, 1996.

SOUZA, C. Políticas Públicas: uma revisão da literatura. Sociologias, Porto Alegre, ano 8, n. 16, p. 20-45, jul./dez. 2006.

VYGOTSKY, L. S. A formação social da mente: o desenvolvimento dos processos psicológicos superiores. São Paulo: Martins Fontes, 1984.

WALLON, H. A evolução psicológica da criança. Lisboa: Edições 70, 1998.

Recebido em 26/o2/13. Aprovado em 17/04/13. 